\title{
RuMO AO AUTOMATISMO SOCIAL? A CONTRIbuição de Naville ${ }^{1}$
}

\author{
Ricardo Colturato FESTI*
}

A reedição na França, em 2016, do livro Vers l'automatisme social? de Pierre Naville permite às novas gerações terem acesso a um dos mais importantes debates ocorridos nos tempos de gestação da Sociologia do Trabalho: o automatismo, a automação industrial e seus impactos sobre o trabalho e o conjunto sociedade. Publicado pela primeira vez em 1963, pela editora Gallimard, suas análises e projeções foram capazes de antecipar questões que atualmente predominam no mundo do trabalho. Por esse motivo, talvez, esta nova publicação reflita o crescente interesse pela obra do autor. Desde sua morte, em 1993, novos livros, artigos e uma biografia sobre Naville foram publicados, além de uma obra reunindo os seus últimos trabalhos ${ }^{2}$. Ainda assim, esses fatos não alteraram a condição de marginalidade do autor na academia francesa, apesar de sua importante contribuição nas décadas de 1950 e 1960. Portanto, o seu reconhecimento, especificamente pela sociologia do trabalho contemporânea, é ainda aquém de sua influência e de suas formulações teóricas.

Naville transitou, ao longo de sua vida, do surrealismo à militância revolucionária, da arte para a academia, da psicologia para a sociologia, nos deixando uma obra extremante heterogênea, testemunho de uma época de grandes transformações sociais e marcada pelo imperativo da ação política. Filho de uma família da alta burguesia parisiense e de tradição intelectual, optou por cursar filosofia na Sorbonne. Conheceu, nesta época, André Breton e Benjamin Péret. Com

\footnotetext{
UNICAMP - Universidade Estadual de Campinas. Colégio Técnico de Limeira. Limeira - SP - Brasil. 13484-332 - ricardofesti@gmail.com.

1 Resenha da obra: NAVILLE, Pierre. Vers l'automatisme social? machines, informatique, autonomie et liberté. Prefácio de Pierre Cours-Saliers. Paris: Éditions Syllpese, 2016. 328 p.

2 As obras mencionadas, contendo artigos de diversos autores comentando a vida e a obra de Naville são: Eliard (1996), Burnier et al. (1997) e Les vies de P. Naville (2007). Em 2007, Cuenot publicou uma generosa biografia e, em 2010, saiu uma coletânea de textos escritos por Naville entre 1988 e 1993.
} 
este, fundou a revista La Révolution surréaliste, importante veículo de expressão do movimento. Após sua passagem pelo mundo artístico e pela literatura revolucionária, Naville aderiu ao Partido Comunista Francês. Encontrou-se com Trotsky em Moscou um dia após a sua expulsão do PC da URSS e, em seguida, aderiu à oposição de esquerda internacional (movimento conhecido, posteriormente, como trotskismo). Rompeu com ela em 1939 e passou a se dedicar, até o final de sua vida, às atividades acadêmicas.

Após uma passagem pela psicologia, Naville migrou para a sociologia, incorporando-se ao Centre d'études sociologiques, ao lado de Georges Friedmann e Alain Touraine ${ }^{3}$. Reuniu em seu entorno uma equipe de pesquisadores com o propósito de investigar a automação e seus efeitos sociais, empreendendo, entre os anos de 1957 e 1959, pela primeira vez na França, em vários ramos industriais, uma vasta investigação empírica. Este trabalho deu origem a um relatório de 741 páginas intitulado L'automation et le travail humain: rapport d'enquête, publicado em 1961. Nesta mesma época, impulsionou a revista Les cahiers d'études de l'automation et des sociétés industrielles com o objetivo de incentivar o debate sobre o tema. O livro Vers l'automatisme social? machines, informatique, autonomie et liberté, publicado em 1963, representou a síntese dessas pesquisas, estudos e reflexões de Naville ${ }^{4}$.

A automação, durante os anos em que foi abordada pelos autores da nascente sociologia do trabalho francesa, ainda era um fenômeno minoritário dentro do mundo industrial. Para ilustrar essa questão, em 1952, ela não empregava nem $8 \%$ da população economicamente ativa dos EUA. Como observou Georges Friedmann (2012, p. 22), "o trabalho, nas fábricas e nos escritórios, nas minas e nos campos, estava longe de ser automatizado". Mas, para Naville, o surgimento da automação a colocava como referência para a compreensão da sociedade capitalista. Apesar da metalurgia ter um baixíssimo índice de automação na década de 1950, era ela quem comandava o conjunto da economia industrial, pois, as "condições de trabalho, salários, garantias, em toda a cadeia, passaram a receber sua impulsão a partir do que se passa no setor de ponta" (NAVILLE, 2016, p.79). A automação poderia ter uma inserção de 8,10 ou $20 \%$ e empregar a minoria da totalidade da força de trabalho que, mesmo assim, cumpriria um papel diretor ${ }^{5}$.

Na mesma perspectiva de Friedmann, Naville compreendia o automatismo como resultado do desenvolvimento das forças produtivas, ou seja, um desdobra-

\footnotetext{
3 Pierre Naville compôs o grupo que fundou a sociologia do trabalho na França ao lado de Jean Stoetzel, Michel Crozier, Jean-Daniel Reynaud, Alain Touraine e Georges Friedmann.

4 Ainda é difícil para o público brasileiro o acesso ao relatório de 1961. Mas, para aqueles que pretendem aprofundar o tema, é fundamental a sua leitura junto ao livro resenhado.

5 O autor projetava uma generalização da automação para o conjunto da sociedade, mas não considerava que as velhas formas de fabricação, como a mecanização, desapareceriam.
} 
mento da evolução da técnica e do maquinário e do processo de divisão do trabalho inaugurado e intensificado pela etapa da mecanização e do parcelamento do trabalho. Nesse sentido, compreendida como um processo histórico, a automação resultaria mais de questões sociais e econômicas do que técnicas. Veja-se:

Não haveria automatismo generalizado sem monopólios e oligopólios, sem mercados protegidos, sem centralização dos transportes, sem produção em massa, sem garantias de estatais, sem grandes investimentos e benefícios correspondentes. Em suma, o automatismo da produção de bens e serviços (...) aparece como a forma técnica generalizada de um certo nível de civilização, inseparável desta. (NAVILLLE, 2016, p. 107)

Embora Marx tenha visualizado no século XIX a fábrica automática ou o autômato mecânico, suas definições estavam longe da automatização industrial materializada na época de Friedmann, Naville e Alain Touraine. Pode-se encontrar em seus textos várias passagens sobre o desenvolvimento da automatização e do automatismo, vistas como partes da própria fase da mecanização da produção. Ele destaca, no capítulo sobre a maquinaria e a grande indústria de $O$ Capital, que a partir do momento em que a máquina de trabalho executa todos os movimentos necessários do processo de trabalho, sem necessitar mais da ajuda humana, nasce um sistema automático de máquinas com a capacidade de ser continuamente melhorado em seus detalhes. Assim, a produção mecanizada atinge sua forma mais desenvolvida "como sistema articulado de máquinas de trabalho movidas por um autômato central através de uma maquinaria de transmissão" (Marx, 2013, p. 455). Mas a automatização mecânica era apenas uma etapa preparatória da automação industrial.

Uma questão importante para Naville, na caracterização da automação, é quem governa o processo de produção, já que ela não se resume a um conjunto de fábricas automáticas. Tampouco ela tem como diferenciador a inversão entre sujeito e objeto na produção, como apontou Marx sobre a constituição da grande indústria. A automação é a gestão destas máquinas por um "cérebro mecânico", em substituição aos antigos ofícios realizados pelos operários. O trabalho tende a se transferir das atividades neuromusculares para as neurosensoriais, diminuindo os esforços físicos e aumentando as tensões relacionadas a vigilância e a supervisão.

O trabalho se concentra, então, sobre as medidas e os controles das operações e dos produtos, ou seja, sobre a supervisão. Segue-se duas transformações gerais na mão-de-obra: manutenção e desenvolvimento de conhecimentos de certos 
mecanismos operacionais para o pessoal de manutenção e de controle de um novo tipo; redução ou manutenção de operadores comuns a um rol igual ou mais subalterno que antes. (NAVILLE, 1961, p. 711-712) ${ }^{6}$

Mesmo sendo um fenômeno minoritário no mundo industrial, Naville pôde apontar alguns dos principais efeitos negativos da automação. O primeiro e mais evidente é a substituição do trabalhador pela máquina e, consequentemente, o crescimento do desemprego crônico. Mas este não tinha ainda a dimensão estrutural do desemprego surgido após a crise capitalista dos anos 1970. Pelo contrário, o espetacular crescimento econômico do pós-guerra impulsionou, nos ramos em que se implementou o novo maquinário, um crescente regime de permutação e rotação nos postos de trabalho de uma mesma empresa (muitas vezes, os operários eram deslocados para outras funções ou para outras plantas). Surgia, portanto, em numerosas fábricas automatizadas, a polivalência dos operários. Além disso, as frequentes mudanças de postos eram facilitadas tanto pela política de formação quanto pela simplicidade que adquiriu o trabalho ${ }^{7}$. Isso levou Naville a concluir que a automação substitui uma divisão de tarefas isoladas por uma distribuição móvel de funções integradas.

Mas a comprovação empírica mais importante das pesquisas de Naville foi que as novas condições criadas pela automação não levaram a uma maior qualificação dos operários. A grande massa que trabalhava no setor automatizado era especializada e sem qualificações. "Muitas das operações intelectuais perdem sua qualificação na medida em que as máquinas substituem não somente os músculos, mas também os cérebros" (NAVILLE, 2016, p. 88). Isso é reforçado pelo fato de que, pela primeira vez, viu-se elevar os níveis salariais sem que a qualificação propriamente dita estivesse vinculada a isso. Nesse sentido, ao produzir uma fortíssima mudança no aspecto da qualificação profissional, toda uma concepção tradicional do métier desmoronou pouco a pouco.

Outro aspecto abordado em seu livro é que a automação acabou por criar novas ocupações e exigiu uma maior cooperação por parte dos operários no processo de trabalho. Isso levou a modificações nas formas de emprego, na jornada de trabalho e na forma de remuneração. Ocorreu também uma reclassificação dos níveis hierárquicos, assim como uma reorganização das funções no interior da fábrica, o que afetou principalmente os trabalhos em equipes ou em grupos.

\footnotetext{
6 Para uma atualização da definição de automação, ver Coriat (1987). Segundo ele, a novidade não estava no maquinário, mas sim em seus suportes e meios, ou seja, na aplicação da informática, da eletrônica e da robótica.

7 É por isso que Bravermann (1987) afirma que, na fábrica automatizada, há mais do taylorismo do que se possa imaginar. O objetivo principal desse sistema é o controle, retirando das mãos dos operários as operações fabris. A máquina automatizada eleva isso à potência.
} 
A supervisão, o controle e a manutenção dos sistemas autônomos tornavam-se cada vez mais indiretos.

Naville chama a atenção ao fato dos indivíduos estarem menos dependentes de uma máquina isolada e mais subordinados aos ciclos de produção integrados. Nesse sentido, ao mesmo tempo em que o processo acentua a alienação, deixando o homem cada vez mais alheio ao funcionamento das máquinas, ele permite aos mesmos "assegurar indiretamente um controle mais flexível, mais completo, mais profundo e amplo sobre um ciclo de produção dado" (NAVILLE, 2016, p. 233). Como resultado, os elementos técnicos tornam-se menos importantes que os econômicos e sociais sobre a determinação das atitudes dos operários. Nesta nova situação, os indivíduos podem até se sentirem mais livres, por não estarem presos a uma única máquina e a um único posto fixo, porém, por estarem melhores agrupados em equipes fortemente estruturadas, cada posto adquire um papel bem determinado com relação aos outros. "Se um operário está ausente, se não executa corretamente sua tarefa, todos os demais sofrem diretamente a consequência do descompromisso" (NAVILLE, 2016, p. 235). Portanto, eles agora sofrem menos o domínio da ferramenta e estão mais submetidos as consignas da supervisão e da organização do trabalho na escala do estabelecimento.

Alguns sistemas técnicos adquiriram tamanha complexidade na fase da automação que é impossível um indivíduo isolado alcançar uma compreensão de sua totalidade. Por isso que, para Naville, a apropriação da máquina pelo homem deve ser iniciada através de um processo capaz de produzir uma elevação do nível da formação profissional, da polivalência nos empregos e da participação na organização das fábricas.

Por fim, vale ressaltar que foi comum entre vários autores da sociologia do trabalho da geração de Naville uma visão contemplativa da evolução técnica e da modernização da sociedade, como podemos ver nesta passagem:

A automação colocou para a humanidade industrial, no Leste e no Oeste, questões tão formidáveis quanto a primeira revolução da máquina do século XIX. Ela é uma aventura técnica, mas também uma aventura social (...). Ela provoca a tentação de uma automação social generalizada, tão temível quanto são extraordinárias as esperanças de liberdade que ela abre. (NAVILLE, 2016, p. 89)

O livro de Naville teve o mérito de problematizar aspectos da automação que seriam, décadas depois, retomados no debate sobre a cibernética. Ao lê-lo, o leitor se depara tanto com as esperanças quanto com os medos do autor sobre a possibilidade de um mundo governado pelo automatismo integral. Apesar de sua visão fortemente marcada por uma contemplação do progresso das forças produtivas, 
sua análise é dialética. É por esse motivo que ainda hoje Vers l'automatisme social? pode ser uma referência para todo pesquisador que queira abordar o fenômeno da automação e do desenvolvimento do maquinário industrial. Obviamente que esta obra, marcada pelo seu tempo, deve ser lida com o devido distanciamento crítico. Não há como abstrair, por exemplo, que hoje a automação é parte fundamental do processo que precarizou e intensificou o trabalho nas últimas décadas. Mas, se o livro for encarado como uma porta de entrada para o debate, os novos pesquisadores terão em suas mãos um poderoso instrumento de reflexão e inspiração para os seus trabalhos.

\section{REFERÊNCIAS}

BRAVERMANN, H. Trabalho e capital monopolista: a degradação do trabalho no século XX. 3a. ed. Rio de Janeiro: LTC, 1987.

CENTRE D'HISTOIRE SOCIALE DU XXE SIÈCLE (ED.). Les vies de Pierre Naville. Villeneuve-d'Ascq: Presses universitaires du Septentrion, 2007.

CUENOT, A. Pierre Naville, 1904-1993 : biographie d'un révolutionnaire marxiste. Nice: Bénévent, 2007.

BURNIER, M. e al. Des sociologues face à Pierre Naville ou L'archipel des savoirs. Paris Montréal: Éd. l'Harmattan, 1997.

ÉLIARD, M. (ED.). Naville, la passion de la connaissance. Toulouse: Presses universitaires du Mirail, 1996.

FRIEDMANN, G. Le travail en miettes: spécialisation et loisirs. Bruxelles: Éd. de l’Université de Bruxelles, 2012.

MARX, K. O Capital. São Paulo: Editorial Boitempo, 2013.

NAVILLE, Pierre. Vers l'automatisme social? machines, informatique, autonomie et liberté. Prefácio de Pierre Cours-Saliers. Paris: Éditions Syllpese, 2016. 328 p.

. Pierre Naville, la passion de l'avenir : dernier cahier, 1988-1993. Paris: M. Nadeau, 2010.

. L'automation et le travail humain : rapport d'enquête, France, 1957-1959. Paris:

Centre national de la recherche scientifique, 1961.

Recebido em 03/07/2016.

Aprovado em 09/06/2017. 